\title{
《分子催化》第五届编辑委员会
}

\section{The Fifth Editorial Board of Journal of Molecular Catalysis}

名誉主编 (Founding Editor-in-Chief)

王弘立 (WANG Hongli)

主编 (Editor-in-Chief)

李树本 (LI Shuben)

副主 编(Associate Editors-in-Chief)

\begin{tabular}{|c|c|}
\hline 李文钊( LI V) & 万惠霖( WAN Huilin) \\
\hline 伏义路(FU Yilu) & 夏春谷(XIA Chungu) \\
\hline 员 (Editorial Board) & (以姓氏笔画为序) \\
\hline -作龙( YU Zuolong) & 王晓来(WANG Xiaolai) \\
\hline 信和(BAO Xinhe) & 安立敦( AN Lidun) \\
\hline 显清 ( QIU Xianqing) & 吕士杰(LU Shijie) \\
\hline 贤均 (LI Xianjun) & 李赫喧( LI Hexuan) \\
\hline 汉卿(WANG Hanqing) & 沈俭一( SHEN Jianyi) \\
\hline 斌(ZHANG Hongbin) & 郑 卓( ZHENG Zhuo) \\
\hline 奕德(XU Yide) & 徐贤伦 (XU Xianlun) \\
\hline 有畅 (XIE Youchang) & 甄开吉 (ZHEN Kaiji) \\
\hline
\end{tabular}

何鸣元(HE Mingyuan)

吕功煊 (LU Gongxuan) (常务)

\begin{tabular}{|c|c|}
\hline 计亮年 (JI Liar & 邓友全( DENG Youquan) \\
\hline 刘汉范( LIU Hanfan) & 孙予罕(SUN Yuhan) \\
\hline 陆维敏 (LU Weimin) & 李全芝(LI Quanzhi) \\
\hline 李永丹(LI Yongdan) & 何 仁(HE Ren) \\
\hline 辛 勤(XIN Qin) & 杨锡尧(YANG Xiyao) \\
\hline 钟邦克 (ZHONG Bangke) & 唐 勇 ( TANG Yong) \\
\hline 索继栓 (SUO Jishuan) & 黄仲涛 (HUANG Zhongta \\
\hline
\end{tabular}

分子催化

FENZI CUIHUA

JOURNAL OF MOLECULAR CATALYSIS (CHINA)

(双月刊 1987 年创刊)

(BIMONTHLY Started in 1987)

第 34 卷第 1 期 (总第 189 期)

Vol 34, No 1

2020 年 2 月

Feb 2020

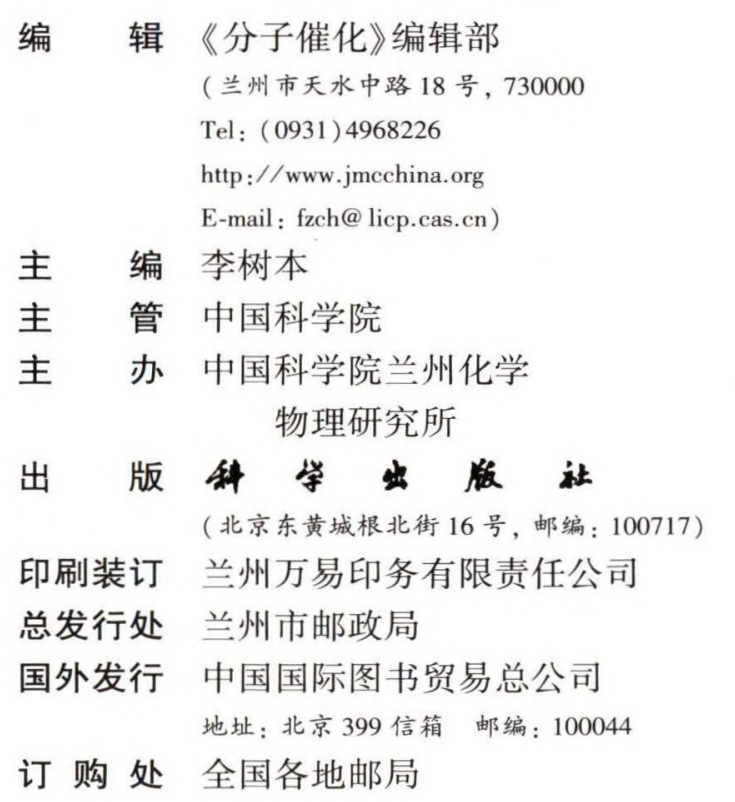

Edited by
Editorial Board of Journal of Molecular Catalysis( China)
( 18 Tianshui Middle Road, Lanzhou 730000
Tel : (0931) 4968226
http://www.jmechina.org
E-mail: fzch@licp.cas.cn)

Chief Editor: LI Shuben

Charged by The Chinese Academy of Sciences

Sponsored by Lanzhou Institute of Chemical Physics,

The Chinese Academy of Sciences

Published by Science Press

(16 Donghuangchenggen, North Street, Beijing 100717)

Printed by Wanyi Printing House of Lanzhou

Distributed by Lanzhou Post Office

Foreign China International Book Trading Add: P.O. Box 399, Beijing 100044, China

Subscription Service: Post Office in China
国内邮发代号 54-69

国内外公开发行
国外发行代号 4747BM 国内定价: 30.00 元

I S SN 1001-3555

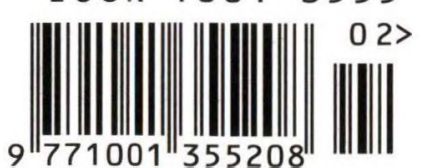

